\title{
A Comparison of AMOS Computer Code Wakefield Real Part Impedances with Analytic Results
}

\author{
D. J. Mayhall, S. D. Nelson
}

November 30, 2000

U.S. Department of Energy

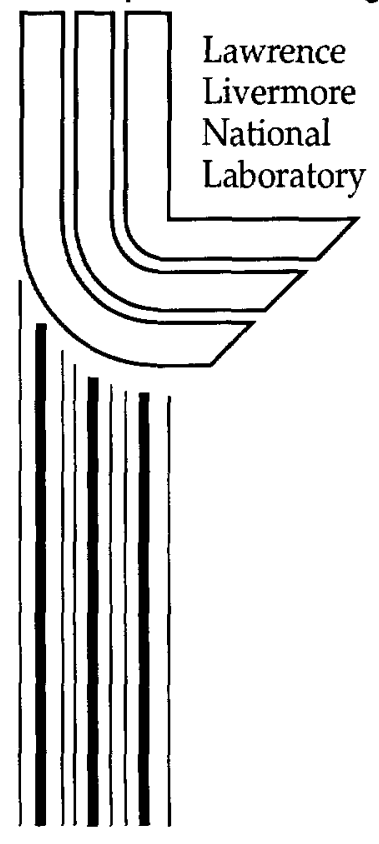




\section{DISCLAIMER}

This document was prepared as an account of work sponsored by an agency of the United States Government. Neither the United States Government nor the University of California nor any of their employees, makes any warranty, express or implied, or assumes any legal liability or responsibility for the accuracy, completeness, or usefulness of any information, apparatus, product, or process disclosed, or represents that its use would not infringe privately owned rights. Reference herein to any specific commercial product, process, or service by trade name, trademark, manufacturer, or otherwise, does not necessarily constitute or imply its endorsement, recommendation, or favoring by the United States Government or the University of California. The views and opinions of authors expressed herein do not necessarily state or reflect those of the United States Government or the University of California, and shall not be used for advertising or product endorsement purposes.

This work was performed under the auspices of the U.S. Department of Energy by the University of California, Lawrence Livermore National Laboratory under Contract No. W-7405-Eng-48.

This report has been reproduced directly from the best available copy.

Available electronically at http://www.doc.gov/bridge

Available for a processing fee to U.S. Department of Energy

And its contractors in paper from

U.S. Department of Energy

Office of Scientific and Technical Information

P.O. Box 62

Oak Ridge, TN 37831-0062

Telephone: (865) 576-8401

Facsimile: (865) 576-5728

E-mail: reports@adonis.osti.gov

Available for the sale to the public from

U.S. Department of Commerce

National Technical Information Service

5285 Port Royal Road

Springfield, VA 22161

Telephone: (800) 553-6847

Facsimile: (703) 605-6900

E-mail: orders@ntis.fedworld.gov

Online ordering: http://www.ntis.gov/ordering.htm

OR

Lawrence Livermore National Laboratory

Technical Information Department's Digital Library

http://www.llnl.gov/tid/Library.html 
A Comparison of AMOS Computer Code Wakefield Real Part Impedances with Analytic Results

\author{
David J. Mayhall and Scott D. Nelson \\ Lawrence Livermore National Laboratory \\ University of California \\ Livermore, CA 94550
}

\title{
A Summary of This Work
}

We have performed eleven AMOS(Azimuthal Mode Simulator)[1] code runs with a simple, right circular cylindrical accelerating cavity inserted into a circular, cylindrical, lossless beam pipe to calculate the real part of the $n=1$ (dipole) transverse wakefield impedance of this structure. We have compared this wakefield impedance in units of ohms $/ \mathrm{m}(\Omega / \mathrm{m})$ over the frequency range of $0-1 \mathrm{GHz}$ to analytic predictions from Equation (2.3.8) of Briggs et al[2]. The results from Equation (2.3.8) were converted from the CGS units of statohms to the MKS units of ohms $(\Omega)$ and then multiplied by $(2 \pi \mathrm{f}) / \mathrm{c}=\omega /$ $c=2 \pi / \lambda$, where $f$ is the frequency in $\mathrm{Hz}, \mathrm{c}$ is the speed of light in vacuum in $\mathrm{m} / \mathrm{sec}, \omega$ is the angular frequency in radians/sec, and $\lambda$ is the wavelength in $\mathrm{m}$. The dipole transverse wakefield impedance written to file from AMOS must be multiplied by c/ $\omega$ to convert it from units of $\Omega / \mathrm{m}$ to units of $\Omega$ The agreement between the AMOS runs and the analytic predictions are excellent for computational grids with square cells $(\mathrm{dz}=\mathrm{dr})$ and good for grids with rectangular cells $(\mathrm{dz}<\mathrm{dr})$. The quantity $\mathrm{dz}$ is the fixed-size axial grid spacing, and $\mathrm{dr}$ is the fixed-size radial grid spacing.

We have also performed one AMOS run for the same geometry to calculate the real part of the $n=$ 0 (monopole) longitudinal wakefield impedance of this structure. We have compared this wakefield impedance in units of $\Omega$ with analytic predictions from Equation (1.4.8) of Briggs et al[1] converted to the MKS units of $\Omega$ The agreement between the two results is excellent in this case. For the monopole longitudinal wakefield impedance written to file from AMOS, nothing must be done to convert the results to units of $\Omega$

In each case, the computer calculations were carried out to $50 \mathrm{nsec}$ of simulation time.

We have also used Equation (2.3.8) to estimate the effect of grid errors from the two-dimensional grid generated by the grid generator, SERPENT[3]. Since SERPENT uses fixed grid cell sizes for $\mathrm{dz}$ and dr, it may not exactly replicate the desired dimensions of the solid model of the analyzed structure. Approximate sizes may thus occur in the computational grid that SERPENT constructs to represent the solid model. The real part of the dipole transverse wakefield impedance for a DARHT accelerator cell was calculated in a Mathematica notebook with Equation (2.3.8) for the frequency range $0-0.7 \mathrm{GHz}$. The corresponding impedances for approximate accelerator cells for grids with square cells of sizes from 0.25 $\mathrm{mm}-3.0 \mathrm{~mm}$ were calculated. For each cell size, the absolute value of the relative error with respect to the exact DARHT cell impedance was calculated, and the maximum value for the examined frequency range was determined. The resulting percent error was plotted versus the grid cell size.

The Implementation of the Equations for Wakefield Impedances

Equation (2.3.8) of Briggs et al[2] for the dipole transverse wakefield impedance was implemented in Mathematica in the form

$$
Z_{t}(n=1)=\frac{-Z_{0} 2 d c}{\pi b^{2} \omega} \ln \left\{[\sin (\omega d / v)]^{2} /\left[(\omega d / v)^{2} H_{1}(\omega)\right]\right\} 8.978 \times 10^{-11} \Omega,
$$

where all the quantities are in the units of the CGS system and the numerical factor at the right end of Equation (1) converts the units to $\Omega$ in the MKS system. The quantity $Z_{0}$ is the intrinsic im- 
pedance of free space, $d$ is the half-length of the cavity, $c$ is the speed of light in free space, $b$ is the beam pipe radius, $\omega$ is the angular frequency of the radiation, $v$ is the electron beam velocity, which is assumed to be $0.999 \mathrm{c}, \operatorname{Im}\{\}$ stands for the imaginary part of the quantity within the curly brackets, and $\mathrm{H}_{1}(\omega)$ is the function defined as

$$
\begin{aligned}
& H_{1}(\omega)=(\omega b / c)\left[J_{1}^{\prime}(\omega b / c) / J_{1}(\omega b / c)-G_{1}^{\prime}(\omega b / c) / G_{1} \omega b / c\right] \\
& (1 / d) \sum_{\rho_{s}}\left(1-e^{-2 d \mu_{s}}\right) /\left[\mu_{s}\left(b^{2} \rho_{s}^{2}-1\right)\right]+\omega^{2} /\left(d c^{2}\right) \sum_{\beta_{1 s}}\left(1-e^{-2 d \varepsilon_{s}}\right) / \varepsilon_{s}^{3},
\end{aligned}
$$

where $J_{1}$ is the first order Bessel function of the first kind, $J_{1}{ }^{\prime}$ is the derivative with respect to the argument of the first order Bessel function of the first kind, and $\rho_{s}, \mu_{s}, \beta_{1 s}$, and $\varepsilon_{s}$ are wavenumbers defined in Briggs et al[2]. The function $\mathrm{G}_{1}(\omega \mathrm{b} / \mathrm{c})$ is defined as

$$
G_{1}(\omega b / c)=J_{1}(\omega b / c)+C_{1} N_{1}(\omega b / c)
$$

where $\mathrm{N}_{1}(\omega \mathrm{b} / \mathrm{c})$ is the first order Bessel function of the second kind, and $\mathrm{C}_{1}$ is given by

$$
C_{1}=\left(i\left[Z_{s} / Z_{0}\right] J_{1}^{\prime}(\omega R / c)-J_{1}(\omega R / c)\right) /\left\{N_{1}(\omega R / c)-i\left[Z_{s} / Z_{0}\right] N_{1}^{\prime}(\omega R / c)\right\} .
$$

The quantity $i$ is the square root of -1 , and $Z_{s}$ is the interior surface impedance at the cavity radius $R$. The function $\mathrm{G}_{1}{ }_{1}(\omega \mathrm{b} / \mathrm{c})$ in Equation (2) is the derivative of $\mathrm{G}_{1}$ with respect to the argument, $\omega \mathrm{b} / \mathrm{c}$, or

$$
G_{1}^{\prime}(\omega b / c)=J_{1}^{\prime}(\omega b / c)+C_{1} N_{1}^{\prime}(\omega b / c)
$$

Equation (1.4.8) of Briggs et al[2] for the monopole longitudinal wakefield impedance was implemented in Mathematica in the form

$$
Z_{l}(\mathrm{n}=0)=-Z_{0}(d /(\pi b)) \operatorname{Im}\left\{[\sin (\omega d / v)]^{2} /\left[(\omega d / v)^{2} H(\omega)\right]\right\} 8.987 \times 10^{-11} \Omega,
$$

where, once again, all the quantities are in CGS units, and the function $\mathrm{H}(\omega)$ is given by

$$
H(\omega)=J_{0}^{\prime}(\omega b / c) / J_{0}(\omega b / c)-G_{0}^{\prime}(\omega b / c) / G_{0}(\omega b / c)+(\omega /(c b d)) \sum_{s}\left(\left(1-e^{-2 d v_{s}}\right) / v_{s}^{3}\right)
$$

The quantity $v_{\mathrm{s}}$ is a wavenumber given by Equation (1.3.11) of Briggs et al[2], and the function $\mathrm{G}(\omega \mathrm{b} / \mathrm{c})$ is given by

$$
G(\omega b / c)=J_{0}(\omega b / c)+C N_{0}(\omega b / c)
$$

where the function $\mathrm{C}$ is given by

$$
C=\left(i\left[Z_{s} / Z_{0}\right] J_{0}^{\prime}(\omega R / c)-J_{0}(\omega R / c)\right) /\left\{N_{0}(\omega R / c)-i\left[Z_{s} / Z_{0}\right] N_{0}^{\prime}(\omega R / c)\right\}
$$

The Geometry of the Structure 
The investigated structure consisted of a lossy, right circular cylindrical pillbox cavity inserted into a lossless, right circular cylindrical beam pipe. The axial length of this structure was nominally $1 \mathrm{~m}$. The radius b of the beam pipe was nominally $7.5 \mathrm{~cm}$. The accelerating cavity joined the beam pipe at $0.5 \mathrm{~m}$ from the beam pipe entrance. The nominal axial length, $2 \mathrm{~d}$, of the cavity was $2.54 \mathrm{~cm}$. The nominal radius $\mathrm{R}$ of the cavity was $27.0 \mathrm{~cm}$. The interior lateral surface of the cavity, that is, the interior surface defined by $R$ constant, had a surface resistance equivalent to $2 Z_{0}=753.4 \mathrm{ohms}$, where $Z_{0}$ is the intrinsic impedance of free space or $376.7 \Omega$ This geometry is shown in Figure 1.

Nominal values:

$$
\begin{aligned}
& \mathrm{a}=50 \mathrm{~cm} \\
& \mathrm{~b}=7.5 \mathrm{~cm} \\
& \mathrm{c}=100 \mathrm{~cm} \\
& \mathrm{~d}=1.27 \mathrm{~cm} \\
& \mathrm{R}=27 \mathrm{~cm}
\end{aligned}
$$

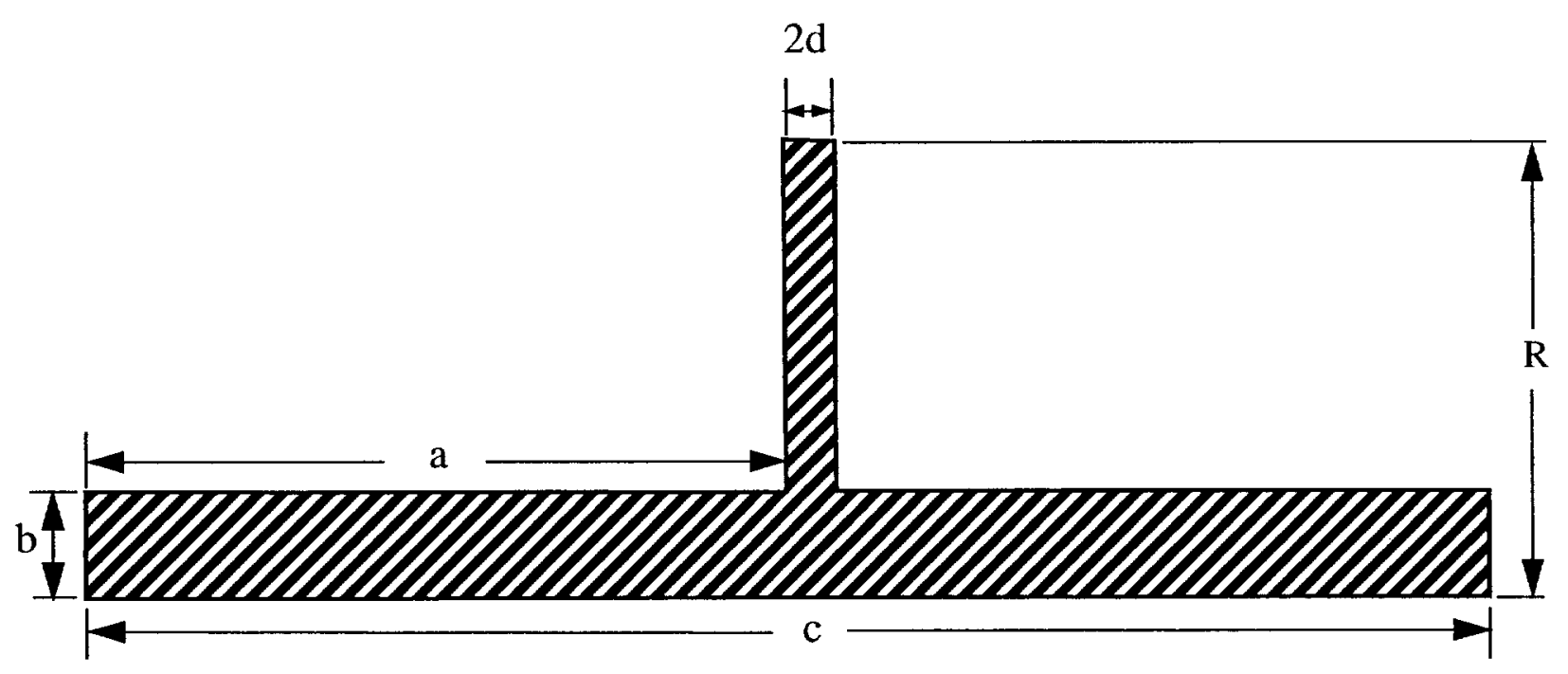

Figure 1. The geometry of the investigated structure.

The actual structural dimensions for each AMOS run differed somewhat from the nominal dimensions due to the fixed-cell-size grid created by the two-dimensional grid generator, SERPENT. The actual dimensions for each dipole mode run are given in Table 1. The runs in Table 1 are ordered roughly by the axial grid cell size, dz. Runs g001 - g004 and g006 - g009 were for grids with square cells. Runs g011 - g013 were for grids with rectangular cells.

Table 1. Summary of AMOs Runs for the Dipole Azimuthal Mode. 


$\begin{array}{cccccccc}\text { Run No. } & \mathrm{dz}(\mathrm{mm}) & \mathrm{dr}(\mathrm{mm}) & \mathrm{R}(\mathrm{cm}) & \mathrm{b}(\mathrm{cm}) & 2 \mathrm{~d}(\mathrm{~cm}) & \mathrm{df}(\mathrm{Hz}) & \text { Maximum difference }(\Omega / \mathrm{m}) \\ \text { g009 } & 6.900 & 6.9 & 26.91 & 7.59 & 2.7600 & 19867070 & 6.03 \\ \text { g008 } & 5.900 & 5.9 & 27.14 & 7.67 & 2.3600 & 19604010 & 4.70 \\ \text { g001 } & 5.000 & 5.0 & 27.00 & 7.50 & 2.5000 & 19518250 & 3.06 \\ \text { g002 } & 4.000 & 4.0 & 27.20 & 7.60 & 2.4000 & 19277270 & 1.65 \\ \text { g003 } & 3.000 & 3.0 & 27.00 & 7.50 & 2.4000 & 19277270 & 1.37 \\ \text { g004 } & 1.900 & 1.9 & 26.98 & 7.41 & 2.6600 & 19261450 & 2.38 \\ \text { g006 } & 1.000 & 1.0 & 27.00 & 7.50 & 2.5000 & 19277280 & 2.72 \\ \text { g007 } & 0.500 & 0.5 & 27.00 & 7.50 & 2.5500 & 19277270 & 3.19 \\ \text { g011 } & 0.500 & 1.0 & 27.00 & 7.50 & 2.5500 & 19277270 & 11.2 \\ \text { g012 } & 0.333 & 1.0 & 27.00 & 7.50 & 2.5308 & 19296640 & 15.8 \\ \text { g013 } & 0.250 & 1.0 & 27.00 & 7.50 & 2.5500 & 19277270 & 18.1\end{array}$

The Comparison Quality Factor

The quality factor used to compare the amount of agreement between the computational and analytic results is the maximum difference in the transverse wakefield impedance in $\Omega / \mathrm{m}$. This quantity is given in the last column of Table 1. This maximum difference is the absolute value of the diffenence between the two types of results at corresponding, equally spaced sample points from $\mathrm{df}$, the sample frequency interval for the AMOS calculation, to slightly greater than $1 \mathrm{GHz}$. The AMOS sample frequency interval df is given in the next-to-last column in Table 1. It differs somewhat for some of the AMOS runs.

The Comparison of Results

As shown in Table 1, the best agreement occurred for Run g 003 for square grid cells at $3 \mathrm{~mm}$ per side. Figure 2 shows the comparison of the AMOS and analytic results for this run. The solid curve shows the analytic transverse wakefield impedance. The curve with the boxes shows the AMOS results. The first peak for the AMOS impedance occurs at $327.7 \mathrm{MHz}$ with the value of $228.9 \Omega / \mathrm{m}$. The second peak in the AMOS impedance occurs at $886.8 \mathrm{MHz}$ with the value, $678.4 \Omega / \mathrm{m}$. Evaluation of the analytic equation via a Mathematica notebook places the first peak of the impedance at about $327.3 \mathrm{MHz}$ with the value, $228.8 \Omega / \mathrm{m}$. The second peak in the analytic impedance occurs at approximately $881.6 \mathrm{MHz}$ with the value, $680.4 \Omega / \mathrm{m}$.

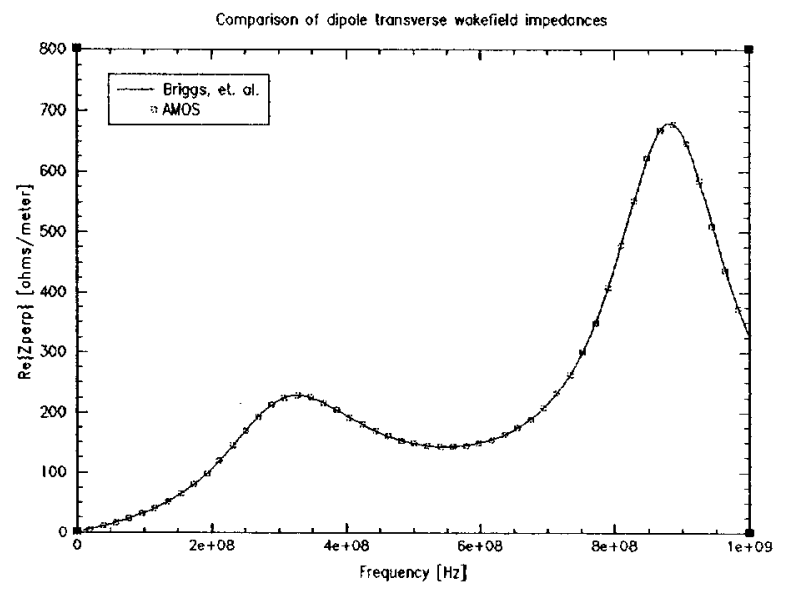

Figure 2. Comparison of the real part of the AmOs and analytic dipole transverse wakefield impedances for $\mathrm{dz}=\mathrm{dr}=3 \mathrm{~mm}$. The solid curve is for the analytic results. The curve with the boxes is for the AmOs results. 
For the square grid cells with sizes greater than and less than $3 \mathrm{~mm}$, the agreement between the results becomes progressively worse as the cell size respectively increases or decreases from $3 \mathrm{~mm}$. Figure 3 shows the comparison of the two results for Run $\mathrm{g} 009$ with $\mathrm{dz}=6.9 \mathrm{~mm}$. The solid curve gives the anaytic results. The curve with the boxes gives the AMOS results. Although the agreement is noticeably worse to the eye than for Run g003 in Figure 2, it is still very good. The first peak in the AMOS impedance in Figure 3 occurs at $337.7 \mathrm{MHz}$ with the impedance value, $250.9 \Omega / \mathrm{m}$. The second peak occurs at 894.0 $\mathrm{MHz}$ with the value of $753.7 \Omega / \mathrm{m}$. For the corresponding analytic results, the first peak occurs at approximately $329.1 \mathrm{MHz}$ with the impedance, $254.2 \Omega / \mathrm{m}$. The second peak occurs at about $885.4 \mathrm{MHz}$ with the value of $755.5 \Omega / \mathrm{m}$.

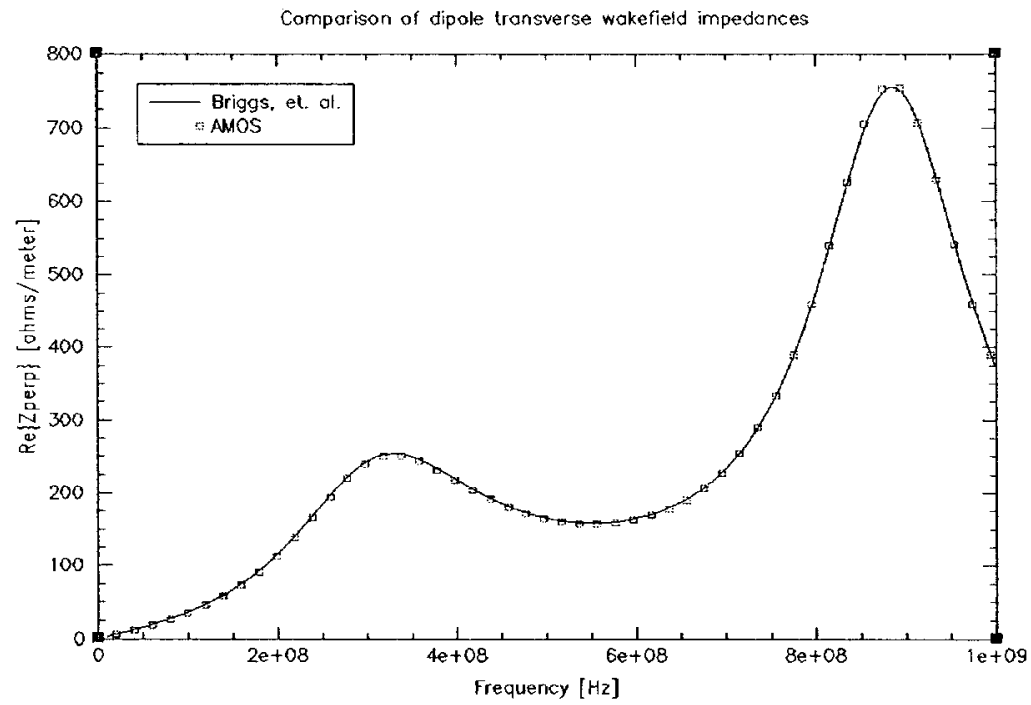

Figure 3. Comparison of the real part of the AmOs and analytic dipole transverse wakefield impedances for $d z=d r=6.9 \mathrm{~mm}$. The solid curve is for the analytic results. The curve with the boxes is for the AMOs results.

The absolute values of the differences between the AMOS results and the Briggs et al[2] results for the dipole transverse wakefield impedances versus frequency for the runs with square grid cells are shown in Figure 4. The absolute values of the differences for the runs with rectangular grid cells are shown in Figure 5 . 


\section{Error in dipole transverse wakefield impedances}

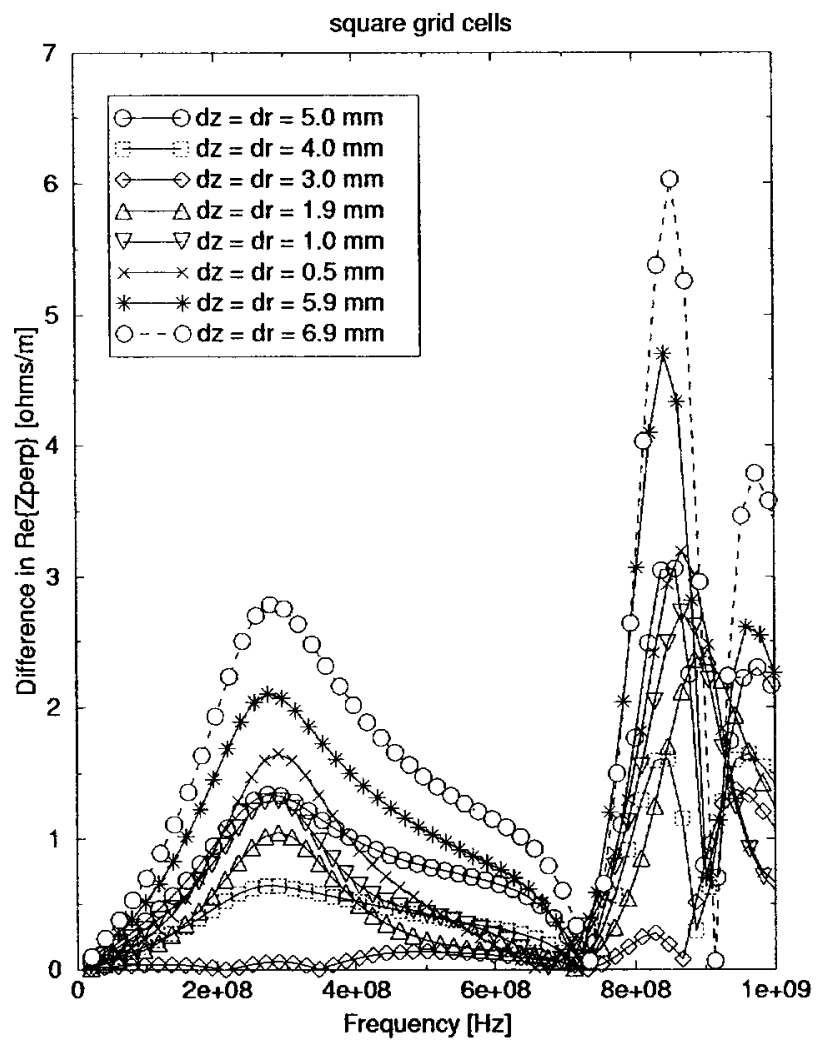

Figure 4. The absolute value of the differences between the Amos results and the analytic results for the dipole transverse wakefield impedances with square grid cells. 


\section{Error in dipole transverse wakefield impedances}

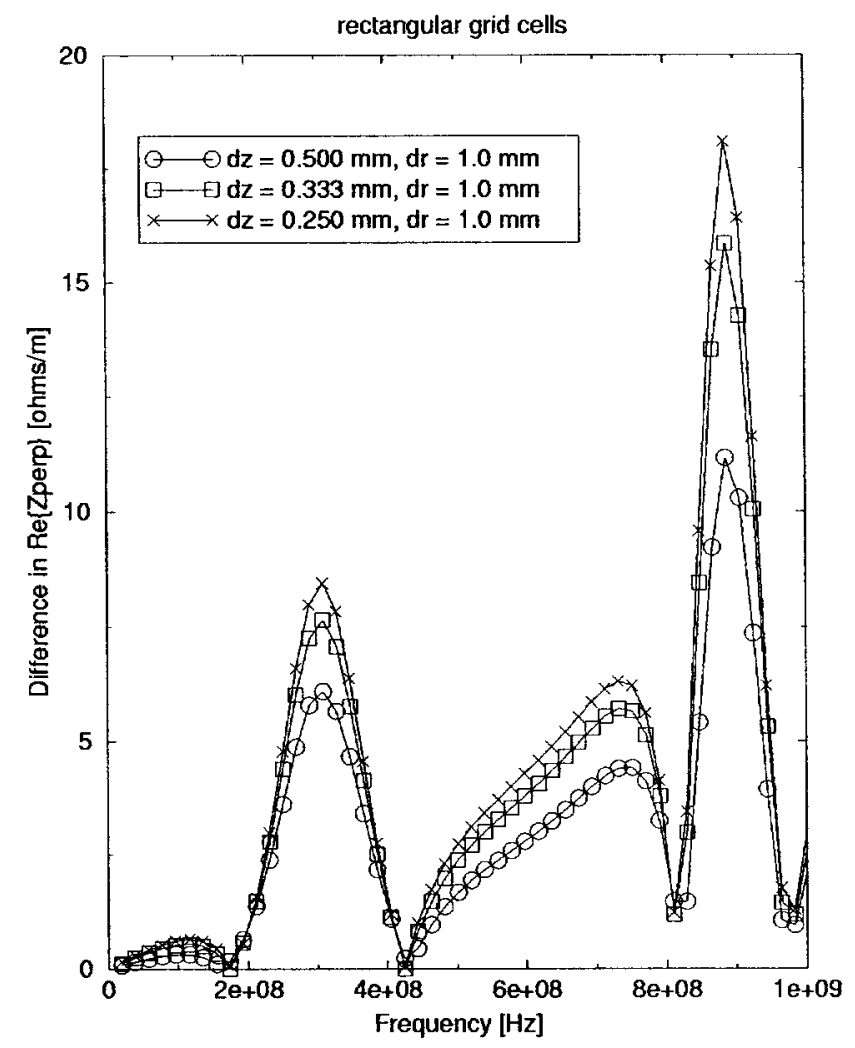

Figure 5. The absolute value of the differences between the AMOs results and the analytic results for the dipole transverse wakefield impedances with rectangular grid cells.

It is interesting that the three runs with rectangular grid cells give worse agreement than the runs with square grid cells. We will define the aspect ratio for the rectangular cells as $\mathrm{dr} / \mathrm{dz}$. Then the aspect ratios for Runs g011, g012, and g013 are 2,3, and 4, respectively. For these three code runs, the radial grid spacing is constant at $1.0 \mathrm{~mm}$. As the aspect ratio increases, the agreement of the dipole transverse wakefield impedance for these 50-nsec runs becomes worse, even though the axial grid refinement increases.

The one AMOS run for the monopole longitudinal wakefield impedance with the square grid cell size of $5 \mathrm{~mm}$ gave excellent agreement with the analytic results from Equation (1.4.8) of Briggs et al[2]. The maximum difference was $0.277 \Omega$ as given in Table 2 . This agreement is shown in Figure 6 . The solid curve gives the analytic results. The curve with the boxes gives the AMOS sample values.

Table 2. Summary of the AMOs Run for the Monopole Azimuthal Mode.
Run No. dz(mm) dr(mm)
$\mathrm{R}(\mathrm{cm})$
$\mathrm{b}(\mathrm{cm}) 2 \mathrm{~d}(\mathrm{~cm})$
g010
5.0
5.0
27.00
$7.50 \quad 2.5000$
$\mathrm{df}(\mathrm{Hz})$
19518250
Maximum difference $(\Omega)$
0.277 


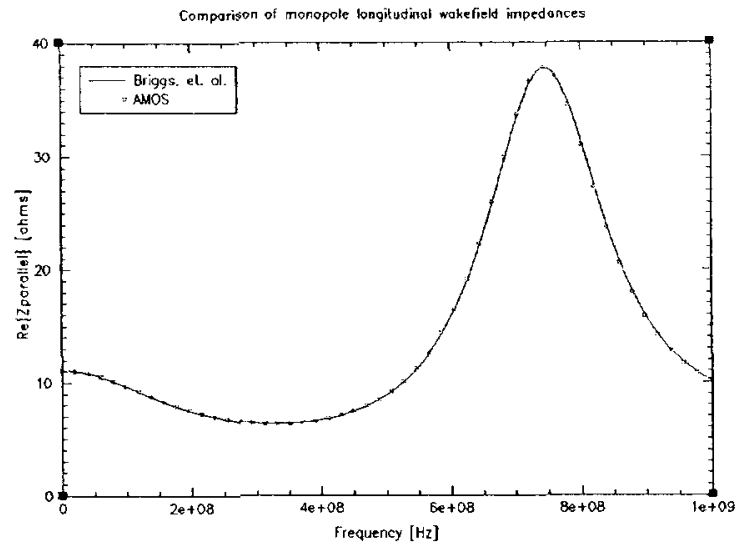

Figure 6. Comparison of the real part of the AMOS and analytic monopole longitudinal wakefield impedances for $d z=d r=5 \mathrm{~mm}$. The solid curve is for the analytic results. The curve with the boxes is for the Amos results.

The absolute value of the percent difference between the analytic results and the AMOS results for the real part of the monopole longitudinal wakefield impedance is shown in Figure 7. The peak value of 0.333 occurs right at the frequency of $1 \mathrm{GHz}$.

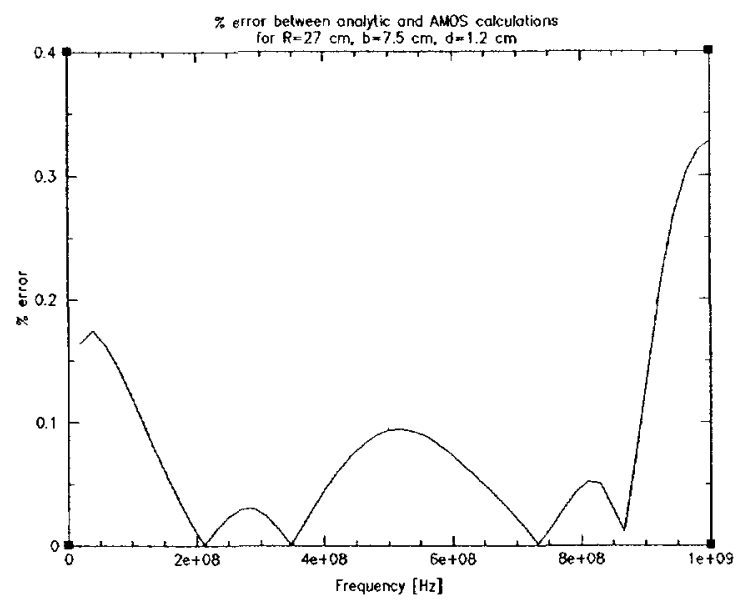

Figure 7. The percent difference for the analytic and AMOS monopole longitudinal wakefield impedance for $d z=d r=5 \mathrm{~mm}$.

\section{Estimstion of the DAHRT Cell Transverse Impedance for Grid Errors}

We have used Equation (2.3.8) of Briggs et al[2] to calculate the real part of the dipole transverse wakefield impedance for the structure formed by the insertion of a DAHRT accelerator cell into a beam pipe. In this case, the beam pipe radius $b$ is $12.6 \mathrm{~cm}$. The axial length of the accelerating cavity, $2 \mathrm{~d}$, is 1 inch or $2.54 \mathrm{~cm}$. The radius of the cavity $\mathrm{R}$ is 3 feet or $91.44 \mathrm{~cm}$. The dipole transverse wakefield impedance for this DAHRT structure in units of $\Omega / \mathrm{m}$ is shown Figure 8 for the frequency range, 0 - $700 \mathrm{MHz}$. Four peaks are seen to occur in this impedance over the chosen frequency range. The first peak is relatively quite small in comparison to the other three. The four peaks occur at the frequencies given in Table 3. 


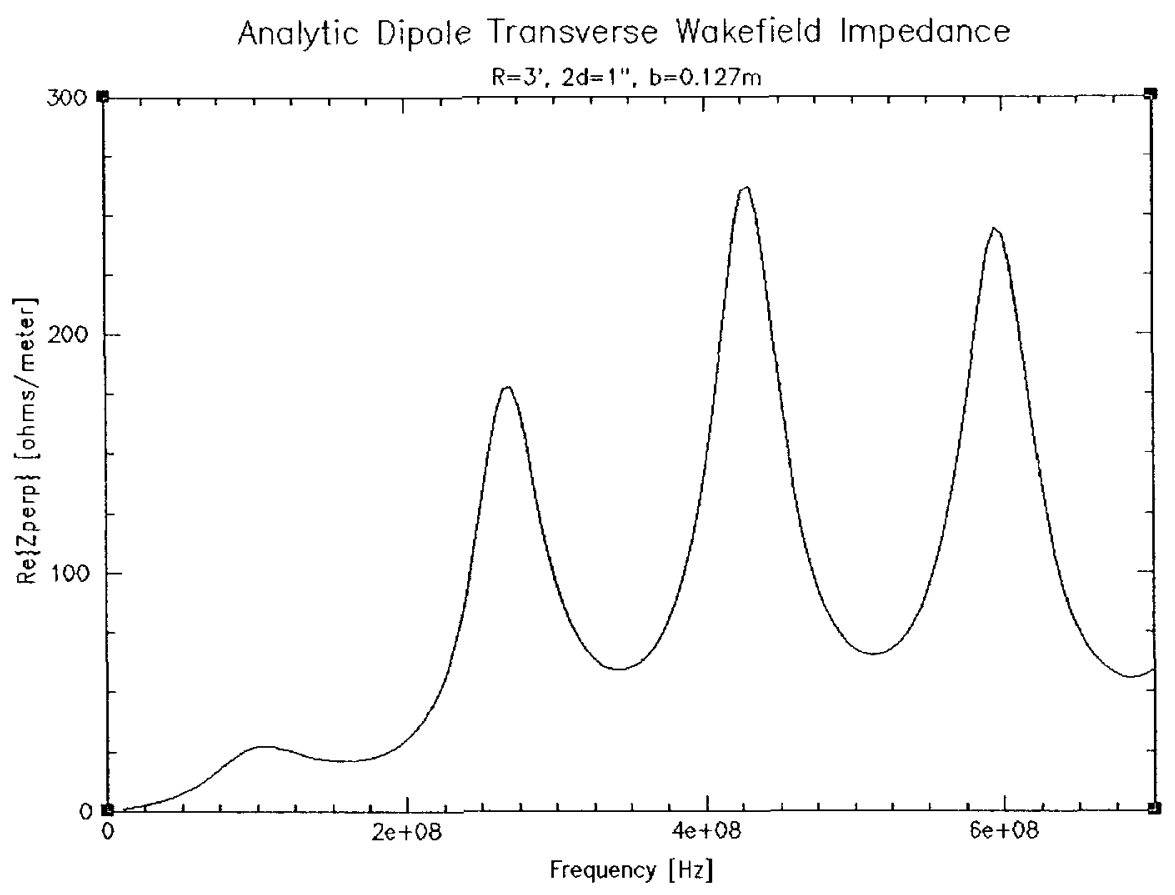

Figure 8. The real part of the dipole transverse wakefield impedance for the DAHRT accelerator cell from 0 to $700 \mathrm{MHz}$.

Table 3. The Locations and Values of the first Four Peaks in the Real Part of the Dipole Transverse Wakefield Impedance for the DAHRT Cell.

$\begin{array}{ccc}\text { Peak No. } & \text { Frequency }(\mathrm{MHz}) & \text { Value }(\Omega / \mathrm{m}) \\ 1 & 105 & 27.49 \\ 2 & 270 & 177.6 \\ 3 & 430 & 261.9 \\ 4 & 595 & 244.2\end{array}$

Because the two-dimensional grid generator, SERPENT, uses fixed grid sizes, $\mathrm{dz}$ and dr, to generate the grid from the solid model, it frequently may not exactly reproduce the dimensions of the features in the solid model for the selected grid cell sizes. The resulting approxcimate grid of the structure causes an error in the calculated impedance when AMOS is run. We have estimated this AMOS grid error by calculating the real part of the dipole transverse wakefield impedance from Equation (2.3.8) with the dimensions SERPENT uses for given square grid cell sizes from $0.25 \mathrm{~mm}$ to $3.0 \mathrm{~mm}$. The structure dimensions, $\mathrm{b}, \mathrm{d}$, and $\mathrm{R}$, for each square grid cell size, $\mathrm{dz}$, are given in Table 4 . We have calculated the wakefield impedance for the grid error over the frequency range, 0 to $700 \mathrm{MHz}$, subtracted it from the wakefield impedance without the grid error at each frequency, taken the absolute value, divided that result by the impedance without the grid error, multiplied the result by 100 , and then determined the maximum value for each grid cell size. This final result is the maximum percent error with respect to the impedance without the grid error. This value is given in the last column of Table 4.

Table 4. Maximum Percent Error in the Real Part of the Dipole Transverse Impedance Versus the Square Grid Cell Size 


$\begin{array}{crrrc}\mathrm{dz}(\mathrm{mm}) & \mathrm{d}(\mathrm{cm}) & \mathrm{b}(\mathrm{cm}) & \mathrm{R}(\mathrm{cm}) & \text { Maximum Percent Error }(\%) \\ 0.25 & 1.2750 & 12.600 & 91.450 & 0.7231 \\ 0.50 & 1.2750 & 12.600 & 91.450 & 0.5830 \\ 0.75 & 1.2750 & 12.600 & 91.425 & 0.6607 \\ 1.00 & 1.2500 & 12.600 & 91.400 & 2.3164 \\ 1.25 & 1.2500 & 12.625 & 91.500 & 2.9676 \\ 1.50 & 1.2750 & 12.600 & 91.500 & 1.4770 \\ 1.75 & 1.3125 & 12.600 & 91.525 & 5.0053 \\ 2.00 & 1.3000 & 12.600 & 91.400 & 3.0088 \\ 2.25 & 1.2375 & 12.600 & 91.350 & 4.1772 \\ 2.50 & 1.2500 & 12.500 & 91.500 & 1.8854 \\ 2.75 & 1.2375 & 12.650 & 91.575 & 5.6024 \\ 3.00 & 1.2000 & 12.600 & 91.500 & 6.2873\end{array}$

Figure 9 shows a plot of the maximum percent error in the real part of the dipole transverse wakefield impedance versus the square grid cell size. As should be expected, the percent error is relatively small for the smaller cell sizes, and largest for the largest cell size. Within the intervening range of cell sizes, the percent error fluctuates as the cell size increases from the smaller sizes to the largest cell size.

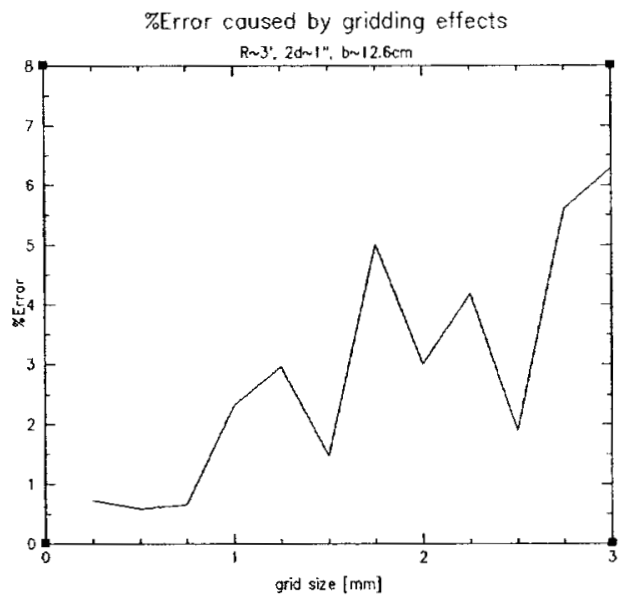

Figure 9. The percent error due to Serpent grid errors for the DAHRT accelerator cell dimensions as the square grid cell varies.

\section{Conclusions}

The AMOS computer code gives results for the real part of the monopole longitudinal wakefield impedance which compare excellently with analytic predictions from Briggs et al[2] for a cylindrical pillbox in a beam pipe. AMOS also gives results for the real part of the dipole transverse wakefield impedance which agree very well with analytic predictions from Briggs et al[2] for the same geometry with square grid cells. AMOs results for the transverse wakefield impedance for rectangular grid cells give good agreement with analytic results.

The real part of the dipole transverse wakefield impedance for a DAHRT accelerator cell has been analytically calculated with Equation (2.3.8) of Briggs et al[2] for the frequency range, 0 to $700 \mathrm{MHz}$. The error due to fixed cell size grid generation has been estimated analytically for the DAHRT cell for square 
cell sizes from $0.25 \mathrm{~mm}$ to $3.0 \mathrm{~mm}$. The maximum percent error varies from $0.723 \%$ at $0.25 \mathrm{~mm}$ to 6.29 $\%$ at $3.0 \mathrm{~mm}$.

\section{References}

1. J. F. deFord, "AMos 2.4 User's Manual," UCRL-MA-127038, Lawrence Livermore National Laboratory, Livermore, CA, 94550, 1997.

2. R. J. Briggs, D. L. Birx, G. J. Caporaso, V. K. Neil, and T. C. Genoni, "Theoretical and Experimental Investigation of the Interaction Impedances and Q Values of the Cells in the Advanced Test Accelerator," Particle Accelerators, Vol. 18, 1985, pp.41-62.

3. S. D. Nelson, “Serpent 2.36 User's Manual," UCRL-MA-138405, Lawrence Livermore National Laboratory, Livermore, CA, 94550, March 8, 2000. 